\title{
Quantum-chemical simulation of the interaction of 2-methyl-5,7- dinitrobenzo[d] oxazole with tetrahydride borate ion by DFT method
}

\author{
C Igor V. Blokhin, ${ }^{1+}$ Yury M. Atroshchenko, ${ }^{1 *}$ Irina V. Shakhkeldyan, ${ }^{1}$ Loik G. Mukhtorov, ${ }^{1}$ \\ Maria B. Nikishina, ${ }^{1}$ Evgenia V. Ivanova, ${ }^{1}$ and Konstantin I. Kobrakov ${ }^{2}$ \\ ${ }^{1}$ Department of Chemistry. Tula State Lev Tolstoy Pedagogical University. \\ Lenina St., 126. Tula, 300026. Russia.Phone:+7 (4872)35-78-08.E-mail: blokhiniv@mail.ru \\ ${ }^{2}$ Department of Organic Chemistry. State University of Russia. A.N. Kosygin (Technology. Design. Art) \\ Sadovnicheskaya St., 33. Moscow, 117997. Russia. Phone: +7 (495)955-35-58. E-mail: kobrakovk@mail.ru
}

*Supervising author; ${ }^{+}$Corresponding author

Keywords: 2-methyl-5,7-dinitrobenzo $[d]$ oxazole, nucleophilic addition, tetrahydride borate ion, anionic $\sigma$-adduct, DFT method.

Abstract

The aim of the work was quantum chemical modeling by the theory of the functional density functional of the interaction of 2-methyl-5,7-dinitrobenzo[ $[d]$ oxazole with tetrahydride borate ion. For this, geometric optimization and calculation of the total energies of the 2-methyl-5,7-dinitrobenzo[ $d]$ oxazole molecule in the gas phase and water were carried out using the DFT/B3LYP/aug-cc-pVDZ method. To determine the likely reaction centers for a nucleophile attack, atomic charges according to Mulliken and NBO charges in the molecule of the initial substrate were established. The largest positive charges according to Mulliken in the studied molecule, both in the gas phase and in water, are concentrated on the carbon atoms C4 and C6, whereas in the case of NBO analysis, such is the carbon atom C2. Analysis of nucleophilic atomic frontal electron densities on the atoms of the substrate showed that from the point of view of orbital control, the attachment of a nucleophile is most likely to the carbon atom in the 4 position. The data obtained are consistent with previous experimental studies in which a rigid base - methoxide ion is attached to a carbon atom $\mathrm{C} 2$, which is a rigid acid reaction center, and a reaction with a soft base - tetrahydride borate ion proceeds along softer acid centers - carbon atoms C4 and C6 of the benzene ring. The calculation of the total energies of the proposed $\sigma$-adducts allowed us to establish that the most thermodynamically stable structure when one hydride ion is attached to the 2-methyl-5,7-dinitrobenzo[d]oxazole molecule is the product of nucleophile addition to the $\mathrm{C} 4$ carbon atom, and in the case of two hydride ions - at positions 4 and 6 of the annelated benzene ring activated by nitro groups. Thus, the calculation of the Mulliken charges, as well as the values of the nucleophilic atomic frontal electron densities at the atoms of the substrate, best reflects the course of the reaction under conditions of orbital control with a tetrahydroborate ion, and NBO charges are better suited to describe the course of the reaction under conditions of charge control.

\section{References}

[1] M.-J. Don, C.-C. Shen, Y.-L. Lin, W. Syu, Jr., Y.-H. Ding, C.-M. Sun. Nitrogen-Containing Compounds from Salvia miltiorrhiza. Journal of Natural Products. 2005. Vol.68. No.7. P.1066-1070. DOI: 10.1021/np0500934

[2] A. Ghani, E.A. Hussain, Z. Sadiq, N. Naz. Advanced synthetic and pharmacological aspects of 1, 3oxazoles and benzoxazoles. Indian Journal of Chemistry. 2016. Vol.55B. P.833-853. DOI: http://nopr.niscair.res.in/jspui/handle/123456789/35019

[3] S.M. Johnson, S. Connelly, I.A. Wilson, J.W. Kelly. Biochemical and structural evaluation of highly selective 2-arylbenzoxazole-based transthyretin amyloidogenesis inhibitors. Journal of medicinal chemistry. 2007. Vol.51. No.2. P.260-270. DOI: https://doi.org/10.1021/jm0708735

[4] S.M. Rida, F.A. Ashour, S.A. El-Hawash, M.M. ElSemary, M.H. Badr, M.A. Shalaby. Synthesis of some novel benzoxazole derivatives as anticancer, anti-HIV-1 and antimicrobial agents. European journal of medicinal chemistry. 2005. Vol.40. No.9. P.949-959. DOI: https://doi.org/10.1016/j.ejmech.2005.03.023

[5] E.H. Sessions, Y. Yin, T.D. Bannister, A. Weiser, E. Griffin, J. Pocas, M.D. Cameron, C. Ruiz, L. Lin, S.C. Schürer. Benzimidazole-and benzoxazole-based inhibitors of RHO kinase. Bioorganic \& medicinal chemistry letters. 2008. Vol.18. No.24. P.6390-6393. DOI: https://doi.org/10.1016/j.bmcl.2008.10.095 
QUANTUM-CHEMICAL SIMULATION OF THE INTERACTION OF 2-METHYL-5,7-DINITROBENZO[D]OXAZOLE ... $40-46$

[6] L.-Q. Sun, J. Chen, K. Takaki, G. Johnson, L. Iben, C.D. Mahle, E. Ryan, C. Xu. Design and synthesis of benzoxazole derivatives as novel melatoninergic ligands. Bioorganic \& medicinal chemistry letters.

2004. Vol.14. No.5. P.1197-1200. DOI: https://doi.org/10.1016/j.bmcl.2003.12.052

[7] R. Edwards, D.J. Cole. Glutathione transferases in wheat (Triticum) species with activity toward fenoxaprop-ethyl and other herbicides. Pesticide biochemistry and physiology. 1996. Vol.54. No.2. P.96104. DOI: https://doi.org/10.1006/pest.1996.0013

[8] I.H. Leaver, B. Milligan. Fluorescent whitening agents - a survey (1974-82). Dyes and Pigments. 1984. Vol.5. No.2. P.109-144. DOI: https://doi.org/10.1016/0143-7208(84)80008-X

[9] M. Taki, J.L. Wolford, T.V. O'Halloran. Emission ratiometric imaging of intracellular zinc: design of a benzoxazole fluorescent sensor and its application in two-photon microscopy. J. Am. Chem. Soc. 2004. Vol.126. No.3. P.712-713. DOI: https://doi.org/10.1021/ja039073j

[10] V.M. Vinogradov, I.L. Dalinger, A.M. Starosotnikov, S.A. Shevelev. Synthesis of 4,6-dinitro-3-Rbenzo[d]isoxazoles and their transformations under the action of nucleophiles. Rus. Chem. Bull. 2001. Vol.50. No.3. P.464-469. DOI: 10.1023/A:1011313324497

[11] L.G. Mukhtorov, E.V. Ivanova, I.V. Blokhin, I.V. Shakhkel'dyan, Yu.M. Atroshchenko. Synthesis of new derivatives of 10-R-1,8-dinitro-3-oxa-5,10-diazatricyclo[6.3.1.0 2.6] dodeca-2 (6), 4-dienes. Russian Journal of Organic Chemistry. 2018. Vol.54. No.9. P.1408-1409. (russian)

[12] L.G. Mukhtorov, I.V. Blokhin, I.V. Shakhkeldyan, Yu.M. Atroshchenko, V.A. Arlyapov, K.I. Kobrakov, and A.N. Shumsky. Quantum chemical and experimental study of anionic $\square$-adducts of 2-methyl-5,7dinitrobenzo[d]oxazole with methoxide ion. Butlerov Communications. 2015. Vol.44. No.12. P.164169. DOI: $10.37952 /$ ROI-jbc-01/15-44-12-164

[13] I.V. Blokhin, L.G. Mukhtorov, Yu.M. Atroshchenko, I.V. Shakhkeldyan, P.V. Strashnov, M.A. Ryabov, K.I. Kobrakov, and A.N. Shumsky. Theoretical modeling of the interaction of 2-R-5,7-dinitrobenzo[d]oxazoles with methoxideion by DFT method. Butlerov Communications. 2017. Vol.49. No.3. P.84-91. DOI: $10.37952 / R O I-j b c-01 / 17-49-3-84$

[14] A.A. Granovsky. Firefly version 8.0. 2016. URL: http://classic.chem.msu.su/gran/firefly/index.html

[15] A.D. Becke. Density-functional thermochemistry. III. The role of exact exchange. J. Chem. Phys. 1993. Vol.98. No.7. P.5648-5652. DOI:https://doi.org/10.1063/1.4869598

[16] C. Lee, W. Yang, R.G. Parr. Development of the Colle-Salvetti correlation-energy formula into a functional of the electron density. Physical review B. 1988. Vol.37. No.2. P.785. DOI:https://doi.org/10.1103/PhysRevB.37.785

[17] P.J. Stephens, F.J. Devlin, C.F. Chabalowski, M.J. Frisch. Ab initio calculation of vibrational absorption and circular dichroism spectra using density functional force fields. J. Phys. Chem. 1994. Vol.98. No.45. P.11623-11627. DOI: 10.1021/j100096a001

[18] Dunning Jr T.H. Gaussian basis sets for use in correlated molecular calculations. I. The atoms boron through neon and hydrogen. J. Chem. Phys. 1989. Vol.90. No.2. P.1007-1023. DOI: https://doi.org/10.1063/1.456153

[19] J. Tomasi, B. Mennucci, R. Cammi. Quantum mechanical continuum solvation models. Chem. Rev. 2005. Vol.105. No.8. P.2999-3094. DOI:10.1021/cr9904009

[20] C.M. Knowles, G.W. Watt. The reduction of benzoxazoles and benzothiazoles in liquid ammonia. $J$. Org. Chem. 1942. Vol.7. No.1. P.56-62. DOI: https://doi.org/10.1021/jo01195a008 